\title{
Germplasm Conservation of Economically Important Medicinal Plant Nyctanthes Arbor-Tristis L. Through Encapsulation Technique and Maintenance Under Slow Growth Condition
}

\section{Awadhesh Kumar Mishra}

Banaras Hindu University

Kavindra Nath Tiwari ( $\sim$ kntiwaribhu@gmail.com )

Banaras Hindu University

Pallavi Mishra

Banaras Hindu University

Sunil Kumar Mishra

Banaras Hindu University

Shailesh Kumar Tiwari

Indian Institute of Vegetable Research

\section{Research Article}

Keywords: Nyctanthes arbor-tristis L., Encapsulation, Start codon targeted (SCoT) primer, Slow growth, Abscisic acid

Posted Date: July 14th, 2021

DOl: https://doi.org/10.21203/rs.3.rs-634822/v1

License: (c) (i) This work is licensed under a Creative Commons Attribution 4.0 International License.

Read Full License

Version of Record: A version of this preprint was published at Plant Cell, Tissue and Organ Culture (PCTOC) on February 5th, 2022. See the published version at https://doi.org/10.1007/s11240-022-022441. 
1 Germplasm conservation of economically important medicinal plant Nyctanthes arbor2 tristis L. through encapsulation technique and maintenance under slow growth condition

3 Awadhesh Kumar Mishra ${ }^{1}$, Kavindra Nath Tiwari*1, Pallavi Mishra ${ }^{1,2}$, Sunil Kumar Mishra ${ }^{3}$, $4 \quad$ Shailesh Kumar Tiwari ${ }^{2}$

$5{ }^{1}$ Department of Botany, MMV, Banaras Hindu University, Varanasi 221005, Uttar Pradesh, 6 India

$7 \quad{ }^{2}$ Crop Improvement Division, Indian Institute of Vegetable Research, Shahanshapur, Varanasi

8 221305, Uttar Pradesh, India

$9{ }^{3}$ Department of Pharmaceutical Engineering and Technology, Indian Institute of Technology, 10 Banaras Hindu University, Varanasi, 221005, Uttar Pradesh, India

$12 *$ Corresponding author address and Telephone No.

13 Dr. KavindraNathTiwari

14 Professor

15 Department of Botany, MMV, Banaras Hindu University, Varanasi, 221005, Uttar Pradesh, India 16 +91 9335668374: fax: +915422367927

17 Email: kntiwari@bhu.ac.in ; kntiwaribhu@gmail.com

18 E-mail addresses:

19 av84.mishra@gmail.com (A.K.Mishra)

20 pallavimishra23@gmail.com (P.Mishra)

21 skmishra.phe@iitbhu.ac.in (S.K.Mishra);

22 tiwarishailu@gmail.com (S.K.Tiwari)

23

24

25

26

27 


\section{Abstract}

29 An efficient encapsulation and germplasm conservation protocol were developed for Nyctanthes arbor-tristis L. In this study the gel matrix containing three percent sodium alginate (SA) and

$31100 \mathrm{mM}$ calcium chloride $\left(\mathrm{CaCl}_{2} \cdot 2 \mathrm{H}_{2} \mathrm{O}\right)$ was found best for the formation of encapsulated seeds

32 from node explant of this economically valuable species. The viability of encapsulated seeds and 33 shoot sprouting potential was optimized. Encapsulated seeds stored at $4^{\circ} \mathrm{C}$ and $24^{\circ} \mathrm{C}$ maintained 34 its viability up to 90 days and showed sprouting potential $42.89 \pm 6.04$ and $33.53 \pm 7.15$ percent 35 respectively. Node explant maintain under slow growth condition up to 180 days on one-eighth $36\left(1 / 8^{\text {th }}\right)$ strength MS medium supplemented with 0.5 percent sucrose found suitable to maintain 37 high span viability percent $(40.28 \pm 2.04)$ with average number of shoots/ node $(1.61 \pm 0.28)$ and 38 shoots length $(1.12 \pm 0.32 \mathrm{~cm})$ respectively. One-eighth $\left(1 / 8^{\text {th }}\right)$ strength MS medium 39 supplemented with 0.5 percent sucrose and enriched with $0.5 \mathrm{mg} / \mathrm{l}$ abscisic acid (ABA) 40 prolonged the viability up to $40.36 \pm 1.01$ percent of explant. The best rooting response was 41 achieved on half (1/2) strength MS medium enriched with $4 \mathrm{mg} / \mathrm{l}$ indole-3-acetic acid (IAA). The 42 rooted plant shows 65 percent survivability in open field condition. The true-to-type clonal 43 fidelity assessment of tissue culture recovered acclimated plants with start codon targeted 44 (SCoT) primer profile shows same banding mobility patterns as with source parent mother plant. 45 The maximum banding profile is monomorphic and consistent. Hence on this basis it confirmed 46 the true-to-type clonal stability among them. The protocols display the novel method for 47 conservation of this species under in-vitro condition and facilitate easy exchange of plant 48 germplasm.

49 Key words Nyctanthes arbor-tristis L.; Encapsulation; Start codon targeted (SCoT) primer; 50 Slow growth; Abscisic acid

\section{Abbreviation:}

52 ABA: Abscisic acid

53 BAP: 6-Benzylaminopurine

54 IAA: Indole-3-acetic acid

55 MS: Murashige and Skoog

56 SA: Sodium alginate

57 SCoT : Start codon targeted 


\section{Background}

Loss of biodiversity is due to deforestation, over exploitation and long-term exposure to environmental stresses. Due to ruthless exploitation and environmental catastrophes germplasm are continuously exposed, causing the sudden loss of valuable germplasm. The world's

62 biodiversity is declining at an unprecedented rate and large number of plant species is registered in Red List of threatened species and over 5000 plant species are critically endangered in stage (IUCN 2017). Due to the increased scientific, commercial attention and overharvesting has placed the medicinal plant species are at risk of extinction. The techniques of tissue culture have focused on practical implementation and provide promising strategies to conserve the specific medicinal plant species under controlled condition.

Encapsulation technology offers an efficient means for conservation and mass clonal recovery of desired plant species. Encapsulation of vegetative propagules has become a potentially cost-effective in clonal propagation system and can be used as an alternative to seeds. Alginate encapsulation provides a viable approach for in vitro germplasm conservation as it combines the advantages of clonal multiplication with those of seed propagation and storage. An encapsulated seed or artificial seed consist of artificially encapsulated embryonic or nonembryonic tissue (shoot tip and node etc.) that are capable of conversion into plantlets in vitro or ex vitro conditions. Earlier, the concept of encapsulated seeds was traditionally based only on the encapsulation of somatic embryos that could be handled like a real seed for transport, storage and sowing. But, in recent years the encapsulation of non-embryogenic vegetative propagules like shoot-tip (Arumugam et al. 2019), axillary buds (Asmah et al. 2011), nodal explants (Prakash et al. 2018; Kundu et al. 2018) and rhizome explant (Sharma et al. 2018) was employed as a suitable alternative way for the maintenance of germplasm. This method is widely used for encapsulated seeds preparation of wide range of plant species including fruits (Fathordoobady et al. 2021), ornamental plants (Hatzilazarou et al. 2020), cardio-protective medicinal tree (Gupta et al. 2014), other different medicinal plants (Ali et al. 2012; Islam and Bari 2012) and woody climber (Sharma and Shahzad 2012). The recovery of plants through encapsulation of vegetative propagules has been reported in other medicinally important plant species like Tylophora indica (Devendra et al. 2011), Ocimum gratissimum (Saha et al. 2014) Sterculia urens (Subhashini Devi et al. 2014) and Urginea altissima (L.f.) Baker (Baskaran et al.2018). 
Encapsulation technology is convenient and reliable technique for conservation of plant genetic resources without apparent risk of genetic instability using minimum space, less labor, less maintenance costs and easy in transference. In recent years, short term storage of germplasm can be achieved by storage of encapsulated seeds at low temperature (Parveen and Shahzad 2014). An alternate method for short to medium-term storage of germplasm is to maintain the explant under slow grwoth conditions (Zayova et al. 2017). Slow growth techniques based on the manipulation of culture conditions and culture media (Zayova et al. 2017), which allow cultures to remain viable under slow growth rate. Conservation under minimal growth condition comprises reducing the incubation temperature, modifying the culture medium (Tyagi et al. 2009), and supplementing with osmotic compounds, such as sucrose (Gopal and Chauhan 2010) to suppress shoot growth. These storage techniques are generally applicable to a wide range of medicinal plant species and extend the ordinary subculture duration from a few weeks to several months. These alternate conservation techniques are less costly and safe to conserve the germplasms of valuable plant species (Epperson et al. 1997). Minimal growth storage is a very simple technique and has been studied in laboratories in other species (Sarasan et al. 2006). Depending on the species, these stored plants can be recovered rapidly when desired.

Nyctanthes arbor-tristis L. is an important antiviral medicinal plant of family Oleaceae. Due to over exploitation coupled with poor seed viability and germination, it is depleted in natural habitat (Sagar and Singh 2004). It is urgently needs to develop the suitable alternate method for its conservation and optimize the good speedy recovery potential of this species. In our knowledge, this is the first report on conservation by short term storage of encapsulated seeds up to prolong duration at low temperature and their efficient, speedy recovery into complete plantlet from encapsulated seeds. We also studied other parameter of interest by conservation of this species under slow growth conditions. Conservation of economically important medicinal plant $N$. arbor-tristis L. by maintaining the node explant under slow growth conditions was reported first time.

The objective of present study was to prepare the encapsulated seeds from in-vitro node explant and to optimize the efficacy of its conversion into complete plantlets. In this study we standardized the protocol for short to medium term storage of encapsulated seeds and to maintain the node explant under slow growth conditions. Recovery of the plants from stored explants and 
true-to-type clonal fidelity of tissue culture recovered acclimatized plants was standardized with start codon targeted (SCoT) molecular markers.

\section{Experimental details}

\section{Preparation and source of explant}

Immature fresh green seeds of $N$. arbor-tristis L. were sampled from ayurvedic orchard of Institute of Medical Sciences, Banaras Hindu University, Varanasi,Uttar Pradesh, India. The adherents present on the surface of seeds were immediately sterilized by following the standard procedure of surface sterilization protocol. After that, under aseptic and sterile conditions in laminar hood, immature embryos were inoculated on growth regulator free full-strength Murashige and Skoog (MS), (1962) nutrient medium. Further after 28 days of culture, the nodal explant (4-8 mm long) was excised from actively growing green, young seedlings and serves as explant source for encapsulation and slow growth conservation.

\section{Encapsulation of nodal explants}

For encapsulation, solution of different concentrations of sodium alginate (SA) (1.0, 2.0, 3.0, $4.0 \% \mathrm{w} / \mathrm{v})$ (HiMedia) and calcium chloride $\left(\mathrm{CaCl}_{2} \cdot 2 \mathrm{H}_{2} \mathrm{O}\right)(25,50,75$ and $100 \mathrm{mM})$ (HiMedia) was prepared using liquid MS medium. The $\mathrm{pH}$ of gel matrix (SA) and complexing agent (Calcium chloride) was adjusted at 5.8 and further autoclave it at $121{ }^{\circ} \mathrm{C}$ at $1.06 \mathrm{~kg} \mathrm{~cm}^{-2}$ ambient pressure for $15 \mathrm{~min}$. For encapsulation, node explant (4-8 $\mathrm{mm}$ long) mixed in each concentrations $(1,2,3$ and $4 \%$ ) of sodium alginate (SA) were poured gently with sterile pipette tips $(7 \mathrm{~mm})$ in the solution of different concentrations of calcium chloride $\left(\mathrm{CaCl}_{2} \cdot 2 \mathrm{H}_{2} \mathrm{O}\right)$ $(25,50,75,100 \mathrm{mM})$ under laminar hood in sterile condition. Node containing droplets were left for another 20 min with continuous shaking in the calcium chloride $\left(\mathrm{CaCl}_{2} \cdot 2 \mathrm{H}_{2} \mathrm{O}\right)$ solution to achieve complete polymerization and proper cross-linking of sodium alginate. After complete polymerization and cross-linking the encapsulated isodiametric, easy-to-handled capsules were selected and washed it 3-4 times with autoclaved distilled water and transfer to sterile filter paper in petri-dish to remove the excess of water. These encapsulated seeds were used for further study.

\section{Sprouting potential of encapsulated seeds}

For optimization of sprouting and shoot proliferation potential, encapsulated seeds were inoculated on MS medium enriched with different concentrations (0.0-5.0 mg/l) of 6Benzylaminopurine (BAP). The medium without BAP was used as control. Data of sprouting 
149

150

151

152

153

154

155

156

157

158

159

160

161

162

163

164

165

166

167

168

169

170

171

172

173

174

175

176

177

178

179

potential of the encapsulated seeds were recorded at the end of 4 weeks of culture in terms of percent sprouting frequency, number and length of sprouted shoots respectively.

Short-term storage of encapsulated seeds and its germination

Erlenmayer flasks containing solid MS medium without sucrose was used for the storage of encapsulated seeds. Flasks containing encapsulated seeds were maintained at $4^{\circ} \mathrm{C}$ and $24^{\circ} \mathrm{C}$ for span of different periods (30, 60, 90 and 180 days). At the end of storage duration, encapsulated seeds were transferred from flask to germination medium (MS medium enriched with $5.0 \mathrm{mg} / \mathrm{l} \mathrm{BAP}$ ). The percent plantlet sprouting frequency of encapsulated seeds and number of shoots per capsule was recorded at the end four weeks from culture initiation.

\section{Maintenance of node explant under slow-growth conditions and its recovery}

To achieve the minimal growth of axillary buds and to increase the duration of subculture intervals, the effect of nutrients of MS medium and concentration of sucrose was evaluated. Node explant were cultured on MS at full strength, half $(1 / 2)$, quarter $(1 / 4)$ and one-eighth $\left(1 / 8^{\text {th }}\right)$ strength MS medium enriched with different percentage (3.0, 1.5 and 0.5) of sucrose. Cultures were incubated for different time span (30, 90, 180 days) and maintained at $24 \pm 2^{\circ} \mathrm{C}$ under a $16 \mathrm{~h} / 8 \mathrm{~h}$ light/dark regime, under the illuminance of $50 \mu \mathrm{mol} \mathrm{m} \mathrm{m}^{-2}$ from white fluorescent tubes (Phillips, India). After storage at different timespan node explant were transferred on MS medium to evaluate their viability percent. After 180 days storage timespan mean number of shoot buds/node and length of axillary buds/nodes was recorded. To confirm the shoot recovery potential of node explant after 180 days storage, it was sub-cultured on shoot recovery medium (MS+ $5.0 \mathrm{mg} / \mathrm{l} \mathrm{BAP)}$ for regrowth. Data based on the mean number shoots/explant and average mean length of shoots was recorded at the ends four weeks from date of culture initiation.

\section{Effect of abscisic acid (ABA) on slow-growth storage of node explant and its recovery}

To study the effect of abscisic acid (ABA), node explant were cultured on one-eighth $\left(1 / 8^{\text {th }}\right)$ strength MS medium containing $0.5 \%$ sucrose and enriched with various concentrations $(0.0$, 0.5, 1.0 and $2.0 \mathrm{mg} / \mathrm{l})$ of ABA. Cultures were stored up-to different time span (30, 90,180 days). The ABA was filter sterilized through $0.45 \mu \mathrm{m}$ millipore filter before adding to the sterilized medium. Cultures were incubated at $24 \pm 2{ }^{\circ} \mathrm{C}$ under a $16 \mathrm{~h} / 8 \mathrm{~h}$ light/dark regime, with the elluminance of $50 \mu \mathrm{mol} \mathrm{m} \mathrm{m}^{-1}$ from white fluorescent tubes (Phillips, India). After the storage at different time span node explant were transferred on MS medium to evaluate the percent viability. After 180 days storage mean number of shoots/node and lengths of shoots were 
recorded. To confirm the shoot recovery potential of nodal explants after 180 days storage, it was sub-cultured on shoot recovery medium $(\mathrm{MS}+5.0 \mathrm{mg} / \mathrm{l} \mathrm{BAP})$ for regrowth. Data based on the responding frequency $(\%)$, mean number shoot/explant and mean length of shoots was recorded at the end of four weeks from culture initiation.

\section{In-vitro rooting and hardening and transfer out of plantlets}

For in-vitro rooting, green, actively growing healthy shoots $(4-5 \mathrm{~cm})$ were excised from sprouted seeds and recovered shoots developed from stored node explants which was cultured on shoot recovery medium for regrowth and cultured individually on half strength (1/2) MS medium enriched with 1 to $8 \mathrm{mg} / \mathrm{l}$ indole-3-acetic acid (IAA) for efficient rooting. The medium without IAA was used as control. The root induction frequency (\%), mean number of roots/shoot and mean root length were noted at the ends of four weeks from culture initiation. The complete plantlets with about one $\mathrm{cm}$ long roots were removed from rooting medium and washed gently with sterile distilled water to remove attached media on roots and transferred to standard plastic cups containing sterilized commercial soil-rite, mixtures of garden soil and sand. The cups covered with clear polythene bags to maintained high humidity and irrigated daily with 1-2 ml of sterilized MS salt solution upto six days. The plants were maintained as such in culture room at $24 \pm 2^{\circ} \mathrm{C}$ and 16-h/day illuminance of $20 \mu \mathrm{mol} \mathrm{m} \mathrm{m}^{-2} \mathrm{~s}^{-1}$ from cool-white fluorescent tubes. After two weeks the poly-bags partially covered. The acclimatized juvenile plantlets with no any morphological abnormalities in growth characteristics was further transferred to pots containing garden soil, soil-rite and sand in the proportion of 1:1:1 and kept in standard greenhouse with controlled temperature and natural sunlight conditions before transfer in to the open field. Assessment of true-to-type clonal stability

For assessment of true-to-type clonal stability, actively growing acclimated plantlets green leaves frozen immediately in liquid nitrogen and was used for tissue grinding and DNA extraction. Comparison between the start codon targeted (SCoT) profile of source parent mother plant and five tissue culture recovered acclimated green actively growing plants were performed. Doyle and Doyle, (1990) methods with modification were used to isolate DNA from leaves. The true-to-type clonal fidelity assessed by the PCR based SCoT (Start codon targeted) primer analysis. SCoT analysis was carried out by using 14 primers (sequence as described by Collard and Mackill, 2009). The gel was prepared with $0.8 \%$ agarose and stained with ethidium bromide dyes. The quality and quantity of isolated DNA was checked by Dyna Quant 200 Fluorimeter. 
211 The PCR reaction consists of $75 \mathrm{ng}$ of template DNA, $0.5 \mu \mathrm{M}$ primer, $2.5 \mathrm{mM} \mathrm{MgCl}, 0.2 \mathrm{mM}$ $212 \mathrm{dNTP}$ (GeNeiTM, Bangalore, India) in $25 \mu \mathrm{l}$ reaction volume, 2U Taq DNA polymerase 213 (GeNeiTM, Bangalore, India) along with suitable buffer (100 mM Tris-Cl; pH 9.0, $50 \mathrm{mM} \mathrm{KCl,}$ 2141 percent Triton X-100). PCR amplification consisted in 35 cycle of denaturation at $94{ }^{\circ} \mathrm{C}$ for 215 four minutes, annealing at $72{ }^{\circ} \mathrm{C}$ for 1 minute and extension at $72{ }^{\circ} \mathrm{C}$ for 8 minutes. After agarose gel electrophoretic separation, amplicons were visualized by exposing the gel through ultraviolet rays under Gel documentation system (Syngene Gel Doc, Syngene, Synoptics Ltd., UK)

218 for scoring the bands. To assess the homogeneity of band profiles, PCR amplification was carried out in triplicate. Data analysis was carried out by scoring well marked high intensity amplified bands. The size of the amplicons was determined by comparing them with that of $1 \mathrm{~Kb}$ DNA ladder (GeNeiTM, Bangalore, India).

Statistical analysis

223

Experiments were conducted thoroughly and arranged in a completely randomized design (CRD) and each experiment usually had three replicates. The data was statistically analyzed using one way analysis of variance (ANOVA) and was applied to detect the significance of differences among the treatment means using Duncan's new multiple range test (DMRT) at $P<$ $227 \quad 0.05$ level.

\section{Experimental outcome}

\section{Encapsulation and sprouting potential}

Results revealed that lower concentrations of sodium alginate (SA) $(1.0$ and $2.0 \% \mathrm{w} / \mathrm{v})$ induced fragile seeds formation which is not easy to handle, while its higher concentration $(4.0 \%)$ affect the shoot emergence from the beads. So ultimately it affects the rate of sprouting potential and recovery of plantlets. Sodium alginate (SA) at 3.0 percent found most suitable for smooth, easy to handle and spherical beads formation without breakage. At this concentration sprouting frequency $(55.73 \pm 1.58 \%)$ of encapsulated seeds was found to be maximum. Similarly, $25 \mathrm{mM}$ calcium chloride $\left(\mathrm{CaCl}_{2} \cdot 2 \mathrm{H}_{2} \mathrm{O}\right)$ did not support good capsule formation. Capsule prepared after polymerization in 50 and $75 \mathrm{mM}$ solution of calcium chloride $\left(\mathrm{CaCl}_{2} \cdot 2 \mathrm{H}_{2} \mathrm{O}\right)$ results low seed sprouting frequency. The calcium chloride $\left(\mathrm{CaCl}_{2} \cdot 2 \mathrm{H}_{2} \mathrm{O}\right)$ at $100 \mathrm{mM}$ found most suitable for the high frequency $(62.79 \pm 1.87)$ of encapsulated seed sprouting (Table1). Thus, explants mixed in 3.0 percent sodium alginate (SA) and completely polymerized in $100 \mathrm{mM}$ 
241 calcium chloride $\left(\mathrm{CaCl}_{2} \cdot 2 \mathrm{H}_{2} \mathrm{O}\right)$ solution found most effective for good encapsulated seeds

242 formation (Table 1; Fig.1A). To check the sprouting response, encapsulated seeds were inoculated on MS medium enriched with different concentrations (0-10 mg/l) of BAP (Fig. 2). Among them the percent sprouting responses were varied significantly and it depends on the concentration of BAP. Medium enriched with $5 \mathrm{mg} / \mathrm{l} \mathrm{BAP}$ as showed in vertical bar, found best for maximum sprouting frequency (82.91 \pm 7.70$)$ of encapsulated seed (Fig.2 A), maximum mean

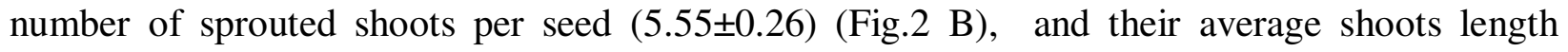
$(2.64 \pm 0.21 \mathrm{~cm})($ Fig.2C; Fig.1 B-C). The sprouting was not observed in untreated encapsulated seeds. The encapsulated seeds stored at $4^{\circ} \mathrm{C}$ and $24^{\circ} \mathrm{C}$ for different time span $(30,60,90$ and 180 days) for short-term conservation were transferred on best shoot multiplication medium (MS+5 $\mathrm{mg} / \mathrm{l} \mathrm{BAP}$ ) to test the viability of stored encapsulated seeds for its sprouting and their efficacy for shoot recovery. The encapsulated seeds stored at $4^{\circ} \mathrm{C}$ for 30 days showed best sprouting response in terms of high percent sprouting frequency $(80.24 \pm 1.01)$ and maximum number of sprouted shoots/seed (6.07士0.19) (Table 2; Fig.1D-F). However, when storage duration was elevated from 30 to 180 days, the viability of encapsulated seeds and sprouting response were successively decreased. Similarly, encapsulated seeds stored at $24^{\circ} \mathrm{C}$ for 30 days showed best sprouting response in terms of percent sprouting frequency $(68.81 \pm 2.59)$ and maximum number of sprouted shoots/ seed $(5.47 \pm 0.35)$. The viability of encapsulated seeds and their sprouting response were drastically decline with increasing the storage time periods from 30 to 180 days. In general it was evident that encapsulated seeds stored at $4^{\circ} \mathrm{C}$ found more responsive for shoot sprouting and conversion potential in to plantlets (Table 2). Encapsulated seeds stored up-to 180 days either at $4^{\circ} \mathrm{C}$ or $24^{0} \mathrm{C}$ were not responsive at all.

\section{Slow growth conservation and recovery}

The slow growth conservation of the $N$. arbor-tristis L. was achieved by maintaining the node explant on MS medium containing full, half $(1 / 2)$, quarter $(1 / 4)$ and one-eighth $\left(1 / 8^{\text {th }}\right)$ strength of salt and enriched with 3.0, 1.5 and 0.5 percent concentration of sucrose (Table 3). Cultures were stored for different span of durations (30, 90 and 180 days) and maintained at $24 \pm 2^{\circ} \mathrm{C}$. The percentage viability of explants, number of shoots/explant and length of shoots were noted. The percentage viability of explants and shoot regeneration efficiency differ significantly, depends on the strength of medium and sucrose concentration. The results revealed that by 
271 increasing the storage span duration, the percent viability of the explants steadily decreased.

272 After 180 days storage, percent survival of node explant was in this order: Full strength $273(30.33 \pm 4.84$ to $54.00 \pm 4.00)>$ half $(1 / 2)$ strength $(26.37 \pm 3.48$ to $46.49 \pm 7.61)>$ quarter $(1 / 4)$ 274 strength $(16.81 \pm 1.07$ to $39.66 \pm 1.54)>$ one-eighth $\left(1 / 8^{\text {th }}\right)$ strength $(18.28 \pm 1.27$ to $40.28 \pm 2.04)$

275 (Table 3). MS medium of different strength when enriched with different percentage (0.5 to 3.0) 276 of sucrose showed significant change in the viability of the explants. In general it was observed 277 that by reducing the percentage of sucrose concentration from 3.0 to 0.5 the proliferation of 278 explants gradually decreased. Axillary buds present in the axil of node explant, its growth into 279 axillary shoots and number of shoot buds/ node was affected by the media strength and concentration of sucrose (Fig.3A-D). In this study the induction of shoot buds/ node was not significantly affected by the medium strength and sucrose concentration, while the length of axillary shoots was affected. Results clearly denote that length of axillary shoots gradually decreased with reducing the media strength and sucrose concentration. Node explant maintained on the one-eighth $\left(1 / 8^{\text {th }}\right)$ strength MS containing 0.5 percent sucrose and maintained up to 180 days found most suitable for reducing the number of shoot bud development $(1.61 \pm 0.28)$ and optimum length of axillary buds (1.12 \pm 0.32$)$.

The one-eighth $\left(1 / 8^{\text {th }}\right)$ strength $\mathrm{MS}$ medium with reduced percentage of sucrose 288 concentration (0.5), enriched with various concentrations $(0-2 \mathrm{mg} / \mathrm{l})$ of ABA (Table 4) were used to enhance the dormancy of axillary buds (Table 4). Media enriched with $0.5 \mathrm{mg} / 1 \mathrm{ABA}$ after 180 days storage showed good viability $(40.36 \pm 1.01)$ of the explants with reduced number of shoot buds/ node $(1.32 \pm 0.11)$ and optimum respective length $(0.50 \pm 0.14 \mathrm{~cm})$ of axillary buds.

To test the shoot regrowth potential of the stored nodal explants maintained on either one293 eighth $\left(1 / 8^{\text {th }}\right)$ strength $\mathrm{MS}+0.5 \%$ sucrose medium and one-eighth $\left(1 / 8^{\text {th }}\right)$ strength $\mathrm{MS}+0.5 \%$ sucrose +0.5 mg/l ABA supplemented medium were further sub-cultured on optimum shoot 296 induction medium (MS+ $5 \mathrm{mg} / \mathrm{l} \mathrm{BAP}$ ) (Fig. 4). At this medium the maximum responding percent frequency for shoot regrowth from node explant was 80.26 \pm 4.26 (Fig. 4A). The maximum mean

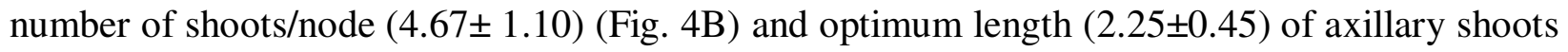
(Fig. 4C; Fig. 3E) was recorded on this medium after 4 weeks from culture initiation. 
Green, healthy elongated shoots $(4-5 \mathrm{~cm})$ were inoculated on half $(1 / 2)$ strength MS medium enriched with different concentrations (1-8 mg/l) of indole-3-acetic acid (IAA) (Table 5).The green microshoots cultured on half (1/2) strength MS medium without IAA unable to root induction. Result revealed that percent frequency (\%) of root induction, number of roots/shoot and root length was depends on the concentration of IAA. The best rooting response with maximum percent root induction efficiency (54.00 \pm 3.05$)$, mean number of roots/shoot (3.25 \pm 0.14$)$ and optimum average root length $(1.11 \pm 0.05 \mathrm{~cm})$ was achieved on half $(1 / 2)$ strength MS medium enriched with $4 \mathrm{mg} / \mathrm{IAA}$ (Fig. 5A, B). Higher concentration of IAA induced green color compact callus at the base of microshoots with no root formation. The untreated green microshoot fails to root induction. The in-vitro well rooted healthy plants were recovered from the culture vials washed gently with water and transferred into plastic cups filled with mixture of garden soil, soil-rite and sand for hardening. These cups were kept for proper acclimatization of plants under green house (Fig.5C, D) and further transfer in the open field. These plants in the field showed 65 percent survival rate under full sun.

\section{Assessment of true-to-type clonal stability}

The true-to-type clonal stability of the plants transferred in to field was assessed using SCoT markers. For confirmation of true-to-type clonal stability, five tissue culture recovered acclimatized plants were selected randomly from the open field along with source parent mother plant $(\mathrm{P})$ and subjected to the genetic stability analysis. The data suggests that no any genetic variation and deformity were observed and banding profiles of recovered plants was similar to the parent mother plant and showed complete monomorphism (Fig. 6). The total seventy eight distinct bands were scored from 14 SCoT primers (SCoT 5, 6, 8, 9, 10, 11, 24, 25, 26, 27, 28, 29, 30 and SCoT 31). The number of scorable band was exists in the range of 2 to 8 per SCoT primers. The total of 444 bands amplified from SCoT primers (Table 6). The maximum bands are consistent, uniform with least variability and no any remarkable differences were observed with source parent mother plant. The identical banding pattern revealed the genetic homogeneity among the recovered plants with source parent mother plant $(\mathrm{P})$. A genetic similarity index was analyzed based binary matrices data on SCoT profile of presence (1) or absence (0) of bands and subjected to cluster analysis by unweighted pair group method and arithmetic averages (UPGMA) clustering method. The Jaccard's average similarity coefficient 0.92-0.99 (Fig.7) with 
the mean value is 0.96 in two clustered group were shown through UPGMA matrix based phenogram.

\section{Discussion}

Successful germplasm conservation of elite species is routed through encapsulation and also based on selection of suitable plant part as the starting plant material, the critical evaluation of factors that affects the gel matrix formation and optimization of germination process for plant retrieval. Encapsulation protocol was influenced by the concentration of sodium alginate (SA) and calcium chloride $\left(\mathrm{CaCl}_{2} \cdot 2 \mathrm{H}_{2} \mathrm{O}\right)$. Calcium alginate capsule with entrapped node differed morphologically in texture, shape, and transparency. The three percent sodium alginate (SA) and $100 \mathrm{mM}$ calcium chloride $\left(\mathrm{CaCl}_{2} \cdot 2 \mathrm{H}_{2} \mathrm{O}\right)$ was found best suitable for formation of capsule and favorable for conversion into plantlets. The similar concentration was also suitable in other species of Picrorhiza kurrooa (Mishra et al. 2011), Ruta graveolens (Ahmad et al. 2012) respectively and fully supports our results. Higher concentration (4\%) of sodium alginate (SA) inhibits the conversion of encapsulated seeds into plantlets, due to its hardness. It suppressed the proper emergence of shoot. Sodium alginate (SA) at lower concentrations (1-2\%) became unsuitable for encapsulation, probably due to reduction in the gelling capacity. It caused the formation of fragile calcium alginate beads and it became difficult to handle. Lower concentration $(25 \mathrm{mM})$ of calcium chloride $\left(\mathrm{CaCl}_{2} \cdot 2 \mathrm{H}_{2} \mathrm{O}\right)$ not only prolonged the ion exchange (polymerization) duration but also favor for fragile beads formation. Encapsulated seeds prepared after polymerization in 50 and $75 \mathrm{mM}$ calcium chloride $\left(\mathrm{CaCl}_{2} \cdot 2 \mathrm{H}_{2} \mathrm{O}\right)$ solution was unsuitable for good germination in this species. In another report of Sphagneticola calendulacea (L.) Pruski (Kundu et al. 2018) $75 \mathrm{mM}$ calcium chloride $\left(\mathrm{CaCl}_{2} \cdot 2 \mathrm{H}_{2} \mathrm{O}\right)$ was considered for encapsulated seed preparation. In case of $N$. arbor-tristis L. $100 \mathrm{mM}$ calcium chloride $\left(\mathrm{CaCl}_{2} .2 \mathrm{H}_{2} \mathrm{O}\right)$ was used for the preparation of good encapsulated seeds, which supports highest frequency of sprouting of encapsulated seeds. This concentration of calcium chloride $\left(\mathrm{CaCl}_{2}\right.$. $2 \mathrm{H}_{2} \mathrm{O}$ ) was focused by other worker in desert date tree (Balanites aegyptiaca Del.) (Varshney and Anis 2014) for preparation of encapsulated seeds. For encapsulation of vegetative buds gelling matrix (sodium alginate) and complexing agent (calcium chloride), play important role in the complexation and hardness of beads (Saeed et al. 2018). Similar type of studies was reported in Punica granatum (Naik and Chand 2006). Conversion of encapsulated seeds into plantlets depends on the species. Singh et al. (2006) reported that conversion of shoot tip encapsulated 
seeds of Withania somnifera (L.) Dunal. into complete plantlets was achieved on MS medium without cytokinin, while in $N$. arbor-tristis L. MS medium supplemented with BAP supports sprouting from encapsulated seeds. Growth regulator (BAP) supplemented media supports recovery of multiple shoots from encapsulated seeds and influenced the developmental process under in vitro condition. A similar finding was reported in Viburnum dentatum (Hatzilazarou et al. 2020) in which BAP is a very common affordable cytokinin which supports high frequency shoot recovery from encapsulated explant.

Short term storage of encapsulated seeds for germplsm conservation was used by other worker (Bhattacharyya et al. 2018). These storage periods may be from few months (Bhattacharyya et al. 2018) to a year (Kaminska et al. 2018). Earlier, low temperature storage of encapsulated propagules has been demonstrated by other worker in Olive (Olea europaea L.) cultivars (Ikhlaq et al. 2010). Encapsulated seeds were stored at $4^{\circ} \mathrm{C}$ was most favorable for the recovery of plantlets of Pseudostellaria heterophylla (Ma et al. 2011). This was probably due to low temperature which slows down the metabolic activities of the encapsulated seeds; hence they remained in quiescent state and are helpful for preservation of nutritive reservoir in the encapsulated seeds during cold storage. The decline in plant recovery from stored encapsulated propagules may be due to oxygen deficiencies in the sodium alginate (SA) bead and its rapid drying as well as dehydration of explant (Faisal and Anis 2007; Ahmad and Anis 2010). Retrieval of plantlets from encapsulated seeds stored at higher temperature $\left(24^{0} \mathrm{C}\right)$ was gradually decreased. In present study recovery of plants from encapsulated seeds stored at $4^{0} \mathrm{C}$ was better than seeds stored at higher temperature $\left(24^{\circ} \mathrm{C}\right)$. Nieves et al. (2003) observed that hydrated encapsulated seeds were difficult to store at room temperature because they lack quiescence and deplete nutritive reservoir which results to low germination potential. The most desirable feature of encapsulated propagules is their capability to retain viability after storage for a reasonable period required for exchange of germplasm between laboratories (Micheli et al. 2007).

Due to economic potential of this species, it was indiscriminately harvested from wild. So, it is urgent need to take the suitable measures for conservation of this species for its sustainable use. In vitro conservation of germplasm was employed by slow growth procedures by other worker in mediterranean globe artichoke Cynara cardunculus var scolymus L. (Tavazza et al. 2015). Slow growth is usually achieved by modifying culture media with supplements of osmotic agents and growth inhibitors as well as by reducing the culture temperature. For inducing 
minimal growth of axillary buds and to increase the subculture intervals node explant of $N$. arbor-tristis L. were maintained on MS basal medium with varying salt concentrations (Full, half $(1 / 2)$, quarter $(1 / 4)$ and one eighth $\left(1 / 8^{\text {th }}\right)$ strength) supplemented with various concentration of sucrose and stored for different time periods (30, 90 and 180 days).

Variation of media strength found effective for maintaining the explant as such for longer period in pear (Ahmed and Anjum 2010) and in Elettaria cardamomum (Tyagi et al. 2009). The reduced concentration of sucrose in the culture medium affects the proliferation percentage in other plant species (Jo et al. 2009). Sucrose is a major component of most tissue culture media. It functions as carbon energy source and osmotic agent (Yaseen et al. 2013). By modifying sucrose level in the media, in vitro growth of tissue cultured plant was modified as reported by other worker (Jo et al. 2009). The other osmoticum like mannitol, sucrose, and sorbitol (El-Bahr 2016), were reported to be good materials to lengthen the storage life of in vitro grown tissues. Interaction of medium with reduced concentration of sucrose clearly indicates that it is highly effective for promoting the dormancy of axillary buds and maintaining the high level of viability of node explant stored up to 180 days of $N$. arbor-tristis L.

Generally, ABA acts as an endogenous growth retardant and inhibits the functions of auxin and cytokinins (Sah et al. 2016). ABA is involved in controlling developmental and physiological processes of plants such as stomata closure, dormancy, seed germination, and leaf senescence (Vishwakarma et al. 2017). It is used for in vitro growth reduction (Cid et al. 2008). ABA induced stomata closure and caused the low metabolic energy utilization (Albert et al. 2017). During culturing shoots with ABA, plants still engaged in photosynthesis that caused the synthesis of storage proteins and lipids. It supports the best growth after recovery. Gopal et al. (2005) succeeded in conserving the nodal segments of potato (Solanum tuberosum L.) for over 18 months by the addition of $2.11 \mathrm{mg} / \mathrm{l}$ of ABA. Results revealed that in N. arbor-tristis L. ABA is also effective for in vitro slow-growth conservation.

Hardening and transfer out of the recovered plantlet after tissue culture is very crucial step for their growth and survival. It is the process of slowly adaptation of plant. So they need step wise acclimatization to successfully re-establish them in the natural environment. When tissue culture plant are systematically transferred from lab environment to natural soil they are exposed to different abiotic stress, like altered temperature, intensity of light, humid condition of 
422

423

424

425

environment and biotic stress like soil micro-flora (Teixeira da Silva et al. 2017). The ultimate success of tissue culture plants depend on its ability to transfer the complete plants from a controlled, aseptic environment to open field successfully while maintaining a low cost with good survival rate. In this study the acclimatized and hardened plants in the field condition showed sixty-five percent survival rates.

True-to-type clonal fidelity is extremely important for planning conservation strategies because some abnormalities can be possible due to long term exposure of culture under in-vitro condition, by repeated sub-culturing. In this direction several DNA based molecular markers were recommended to prove true-to-type clonal genetic uniformity and stability of regenerates. Molecular markers have been utilized for variety of purposes including examination of genetic relationships between individuals and soma-clonal variations (Kalia et al. 2011). Among various markers, Start codon targeted polymorphism (SCoT) analysis was the simplest methods and used to assess the phenotypic and cytogenetic uniformity and are highly discriminative and reliable (Seth et al. 2017). In present communication recovered plants, showed true-to-type clonal fidelity with source parent mother plant $(\mathrm{P})$ and it was proved by SCoT marker with none of the band showed polymorphism. The similarity coefficient revealed that in vitro recovered plants were true-to-type with the source parent mother plants and no any genetic variations induced under in-vitro condition. Start codon targeted DNA polymorphism (SCoT) is a type of DNA marker based on the conserved region flanking translation start codon 'ATG' (Collard and Mackill 2009). The assessment of true-to- type clonal stability by SCoT marker has been extensively studied in other medicinal plants such as Cleome gynandra (Rathore et al. 2014), Citrullus lanatus (Vasudevan et al. 2017) and Tecomella undulate (Chhajer et al. 2017) by different workers.

\section{Conclusion}

In summary, the result shows the best protocol for germplasm conservation of this economically important antiviral medicinal plant species. The germplasm in the form of encapsulated seeds maintain under low temperature and node explant maintained under slow growth condition up to prolong duration shows the good viability and better plantlet recovery potential. The abscisic (ABA) enhance the dormancy of the axillary buds and prolong the survival viability of node 
451 explant. The good rooting is achieved when $4-5 \mathrm{~cm}$ green elongated juvenile actively growing 452 shoots were culture on half (1/2) strength MS medium supplemented with $4.0 \mathrm{mg} / 1$ indole-3-acetic 453 acids (IAA).Well rooted juvenile plants acclimatized properly with standard protocol under well 454 maintained green-house condition. Acclimated plant showed 65 percent survivability in open 455 field under full sun. The acclimated plants show true-to-type clonal fidelity with no any physical 456 abnormalities with source parent mother plants. True-to-type clonal fidelity among recovered

457 plants by SCoT primers confirmed that the developed protocol did not induced genetic changes 458 under in-vitro condition. Thus in conclusion the outcome of optimized protocol provides new 459 insight and has better suitability for short term conservation of germplasm of this value added 460 economical antiviral plant. Thus, the finding proved effectiveness to protect this species in 461 feasible way from habitat loss and other catastrophically degraded environment.

\section{Acknowledgement}

463 The author Awadhesh Kumar Mishra (AKM) is thankful to University Grants Commission 464 (UGC), New Delhi, India for fellowship support throughout the study of this work.

\section{Author's contributions}

466 Author AKM, design, writing the manuscript and completed all experimental work. PM and SKT 467 technically help in the analysis of data. KNT and SKM, is involve in proofreading and finally 468 revise and agreed to the publication of manuscript.

\section{Conflicts of interest}

470 There is no conflict of interest in contributing authors for publication.

\section{$471 \quad$ References}

472 Ahmad N, Anis M (2010) Direct plant regeneration from encapsulated nodal segments of Vitex $473 \quad$ negundo. Biol Plant 54:748-752.

474 Ahmad M, Anjum MA (2010) In vitro storage of some pear genotype with the minimal growth 475 technique. Turk J Agri For 34: 25-32. 
Ahmad N, Faisal M, Fatima N, Anis M (2012) Encapsulation of microcuttings for propagation and short-term preservation in Ruta graveolens: a plant with high medicinal value. Acta Physiol Plant 34: 2303-2310.

Albert R, Acharya BR, Jeon BW, Zañudo JGT, Zhu M, Osman K, Assmann SM (2017) A new discrete dynamic model of ABA-induced stomatal closure predicts key feedback loops. PLoS Biol 15: 2017. e2003451.https://doi.org/10.1371/journal.pbio.2003451.

Ali A, Gull I, Majid A, Saleem A, Naz S, Naveed NH (2012) In vitro conservation and production of vigorous and desiccate tolerant synthetic seeds in Stevia rebaudiana. J Med Plant Res 6:1327-1333

Arumugam G, Sinniah UR, Swamy MK, Lynch PT (2019) Encapsulation of in vitro Plectranthus amboinicus (Lour.) Spreng. shoot apices for propagation and conservation.3 Biotech 9: 298. https://doi.org/10.1007/s13205-019-1831-4.

Asmah HN, Hasnida HN, Zaimah NAN, Noraliza A, Salmi NN (2011). Synthetic seed technology for encapsulation and regrowth of in vitro-derived Acacia hyrid shoot and axillary buds. Afr J Biotechnol. 10: 7820-7824.

Baskaran P, Kumari A, Staden JV (2018) In vitro propagation via organogenesis and synthetic seeds of Urginea altissima (L.f.) Baker: a threatened medicinal plant.3 Biotech 8: 18. https://doi.org/10.1007/s13205-017-1028-7.

Bhattacharyya P, Kumar V, Staden JV (2018) In vitro encapsulation based short term storage and assessment of genetic homogeneity in regenerated Ansellia africana (Leopard orchid) using gene targeted molecular markers. Plant Cell Tiss Organ Cult 133: 299-310.

Chhajer S, Jukanti AK, Kalia RK (2017) Start codon targeted (SCoT) polymorphism-based genetic relationships and diversity among populations of Tecomella undulata (Sm.) Seem -an endangered timber tree of hot arid regions. Tree Genet Genom 13: 84, 2017.DOI 10.1007/s11295-017-1169-1.

Cid B, Carvalho LPY, Luiz LCB (2008) Importance of abscisic acid (ABA) in the in vitro conservation of cassava (Manihot esculenta Crantz). Chilean J Agri Res 68: 304-308.

Collard BCY, Mackill DJ (2009) Start codon targeted (SCoT) polymorphism: a simple noval DNA marker technique for generating gene -targeted marker in the plants. Plant Mol Biol Rep 27: 86-93. 
Devendra BN, Srinivas N, Naik GR (2011) Direct somatic embryogenesis and synthetic seed production from Tylophora indica (Burm.f.) Merrill an endangered, medicinally important plant. Int J Bot 7: 216-222.

Doyle JJ, Doyle JL, (1990) Isolation of plant DNA from fresh tissue. Focus 12: 13-15.

El-Bahr MK, Abd EL-Hamid A, Matter MA, Shaltout A, Bekheet SA, El-Ashry AA (2016) In vitro conservation of embryogenic cultures of date palm using osmotic mediated growth agents. J Gen Eng Biotechnol 14: 363-370.

Epperson E, Pachio DH, Guevara CL (1997) A cost analysis of maintaining Cassava plant genetic resources. Crop Sci 37: 1641-1649.

Faisal M, Anis M (2007) Regeneration of plants from alginate encapsulated shoots of Tylophora indica (Burm. f.) Merrill, an endangered medicinal plant. The J Hort Sci Biotechnol 82: 351354.

Fathordoobady F, Jarzebski M, Singh AP, Guo Y, Manap YA (2021) Encapsulation of betacyanins from the peel of red dragon fruit (Hylocereus polyrhizus L.) in alginate microbeads. Food Hydrocoll 113:106535.https://doi.org/10.1016/j.foodhyd.2020.106535.

Gopal J, Chauhan NS (2010) Slow growth in vitro conservation of potato germplasm at low temperature. Potato Res 53:141-149.

Gopal J, Chamail A, Sarkar D (2005) Use of microtubers for slow growth in vitro conservation of potato germplasm. PGR Newslett 141: 56-60.

Gupta AK, Harish, Rai MK, Phulwaria M, Agarwal T, Shekhawat NS (2014) In vitro propagation, encapsulation, and genetic fidelity analysis of Terminalia arjuna: a cardioprotective medicinal tree. Appl Biochem Biotechnol 173:1481-1494.

Hatzilazarou S, Kostas S, Joachim M, Economou A (2020) Regeneration of Viburnum dentatum L. from alginate-encapsulated shoot explants after short-term cold storage and assessment of genetic stability using ISSR analysis. Agronomy 10: 1660; doi:10.3390/agronomy10111660.

Ikhlaq M, Hafiz IA, Micheli M, Ahmad T, Abbasi NA, Standardi A (2010) In vitro storage of synthetic seeds: Effect of different storage conditions and interval of their conversion ability. Afr J Boitechnol 9: 5712-5721.

Islam MS, Bari MA (2012).In vitro regeneration protocol for artificial seed production in an important medicinal plant Mentha arvensis L. J Bio-Sci 20: 99-108. 
IUCN (2017) IUCN red list of threatened species. 2017. http://www.iucnredlist. Org.

Jo EA, Tewari RK, Hahn EJ, Paek KY (2009) In vitro sucrose concentration affects growth and acclimatization of Alocasia amazonica plantlets. Plant Cell Tiss Organ Cult 96: 307-315.

Kalia RK, Rai MK, Kalia S, Singh R, Dhawan AK (2011) Microsatellite markers: an overview of the recent progress in plants. Euphytica 177: 309-334.

Kamińska M, Gołębiewski M, Tretyn A, Trejgell A (2018) Efficient long-term conservation of Taraxacum pieninicum synthetic seeds in slow growth conditions. Plant Cell Tiss Organ Cult 132: 469-478.

Kundu S, Salma U, Ali Md N, Mandal N (2018) Conservation, ex vitro direct regeneration, and genetic uniformity assessment of alginate encapsulated nodal cuttings of Sphagneticola calendulacea (L.) Pruski. Acta Physiol Plant, 40: 53, 2018. https: //doi.org/10.1007/s11738018-2633-8.

Ma XM, Wu CF, Wang GR (2011) Application of artificial seeds in rapid multiplication of Pseudostellaria heterophylla. Afr J Biotechnol 10, 15744-15748.

Micheli M, Hafiz IA, Standardi A (2007) Encapsulation of In vitro derived explants of Olive (Olea europaea L.cv.Moraiolo) II. Effect of storage on capsule and derived shoot performance. Scient Horticult 113: 286-292.

Mishra J, Singh M, Palni LMS, Nandi SK (2011) Assessment of genetic fidelity of encapsulated microshoots of Picrorhiza kurrooa. Plant Cell Tiss Organ Cult 104: 181-186.

Murashige T, Skoog F (1962) A revised medium for rapid growth and bio assays with tobacco tissue cultures. Physiol Plant 15: 473-497.

Naik SK, Chand PK (2006) Nutrient-alginate encapsulation of in vitro nodal segment of pomegranate (Punica granatum L.) for germplasm distribution and exchange. Sci Horticult, 108: $247-252$.

Nieves N, Zambrano Y, Tapia R, Cid M, Pina D, Castillo R (2003) Field performance of artificial seed derived sugarcane plants. Plant Cell Tiss Organ Cult 75: 279-282.

Parveen S, Shahzad A (2014) Encapsulation of nodal segments of Cassia angustifolia Vahl. for short-term storage and germplasm exchange. Acta Physiol Plant 36, 635-640.

Prakash AV, Nair DS, Alex S, Soni KB, Viji MM, Regunath BR (2018) Calcium alginate encapsulated synthetic seed production in Plumbago rosea L. for germplasm exchange and distribution. Physiol Mol Biol Plants24:963-971. 
Rathore NS, Rai MK, Phulwaria M, Rathore N, Shekhawat NS (2014) Genetic stability in micropropagated Cleome gynandra revealed by SCoT analysis. Acta Physiol Plant 36: 555559.

Sagar R, Singh JS (2004) Local plant species depletion in a tropical dry deciduous forest of northern India. Envi Cons 31: 55-62.

Saeed T, Sahzad A, Ahmad N, Praveen S (2018) High frequency conversion of nonembryogenic synseeds and assessment of genetic stability through ISSR markers in Gymnema sylvestre. Plant Cell Tiss Organ Cult 134:163-168.

Sah SK, Reddy KR, Li J (2016) Abscisic acid and abiotic stress tolerance in crop plants. Front Plant Sci 7: 571. https://doi.org/10.3389/fpls.2016.00571.

Saha S, Sengupta C, Ghosh PD (2014) Molecular and phytochemical analyses to assess genetic stability in alginate-encapsulated microshoots of Ocimum gratissimum L. following in vitro storage. Nucleus 57: 33-43.

Sarasan V, Cripps R, Ramsay MM, Atherton C, Mcmichen M, Predergast G, Rowntree JK, (2006) Conservation in vitro of threatened plants- progress in the past decade. In Vitro Cell Dev Biol -Plant 42, 206-214.

Seth S, Rath SC, Rout GR, Panigrahi J (2017) Somatic embryogenesis in Abutilon indicum (L.) Sweet and assessment of genetic homogeneity using SCoT markers. Plant Biosys 151: 704714.

Sharma S, Shahzad A (2012) Encapsulation technology for short-term storage and conservation of a woody climber, Decalepis hamiltonii Wight and Arn. Plant Cell Tiss Organ Cult 111:191-198.

Sharma SK, Patil A, Agnihotri AK, Mehrotra S (2018) In vitro conservation of Alectra chitrakutensis: a critically endangered root parasitic plant of high medicinal importance. Acta Physiol Plant 40:29. https://doi.org/10.1007/s11738-018-2606-y.

Singh AK, Varshney R, Sharma M, Agarwal SS, Bansal KC (2006) Regeneration of plants from alginate-encapsulated shoot tips of Withania somnifera (L.) Dunal, a medicinally important plant species. J Plant Physiol 163, 220-223.

Subhashini Devi P, Satyanarayana B, Arundhati A, Raghava Rao T (2014) Plant regeneration from encapsulated nodal segments of Sterculia urens Roxb. an endangered gum-yielding tree. J Crop Sci Biotech 17:21-25. 
Tavazza R, Rey NA, Papacchioli V, Pagnotta MA (2015) A validated slow-growth in vitro conservation protocol for globe artichoke germplasm: A cost-effective tool to preserve from wild to elite genotypes. Sci Horticult 197: 135-143.

Teixeira da Silva JA, Hossain MM, Sharma M, Dobranszki J, Cardoso JC, Songjun Z (2017) Acclimatization of in-vitro-derived Dendrobium. Hort Plant J 3:110-124.

Tyagi RK, Goswami R, Sanayaima R, Singh R, Tandon R, Agrawal A (2009) Micropropagation and slow growth conservation of cardamom (Elettaria cardamomum, Maton). In Vitro Cell Dev Biol-Plant 45:721-729.

Varshney A, Anis M (2014) Synseed conception for short-term storage, germplasm exchange and potentialities of regeneration genetically stable plantlets of desert date tree (Balanites aegyptiaca Del.). Agrofor Syst 88: 321-329.

Vasudevan V, Subramanyam K, Elayaraja D, Karthik S, Vasudevan A, Manickavasagam M (2017) Assessment of the efficacy of amino acids and polyamines on regeneration of watermelon (Citrullus lanatus Thunb.) and analysis of genetic fidelity of regenerated plants by SCoT and RAPD markers. Plant Cell Tiss Organ Cult 130: 681- 687.

Vishwakarma K, Upadhyay N,Kumar N, Yadav G, Singh J, Mishra RK, Kumar V, Verma R, Upadhyay RG, Pandey M, Sharma S (2017) abscisic acid signaling and abiotic stress tolerance in plants: a review on current knowledge and future prospects. Front Plant Sci 8:161.doi: 10.3389/fpls.2017.00161.

Yaseen M, Ahmad T, Sablok G, Standardi A, Hafiz IA (2013) Review: role of carbon sources for in vitro plant growth and development. Mol Biol Rep 40: 2837-2849.

Zayova E, Nedev T, Dimitrova L (2017) In Vitro storage of Stevia rebaudiana Bertoni under slow growth conditions and mass multiplication after storage, Bio Bullet 3: 30-38. 
626 Table 1 Establishment of sodium alginate (SA) and calcium chloride $\left(\mathrm{CaCl}_{2} \cdot 2 \mathrm{H}_{2} \mathrm{O}\right)$ 627 concentrations for encapsulated seeds preparation and sprouting frequency of encapsulated seeds 628 of N. arbor-tristis L.

\begin{tabular}{cccc}
\hline $\begin{array}{c}\text { Sodium alginate } \\
\text { concentration }(\%)\end{array}$ & $\begin{array}{c}\text { Sprouting frequency } \\
(\%)\end{array}$ & $\begin{array}{c}\text { Calcium chloride } \\
\text { concentration }(\mathbf{m M})\end{array}$ & $\begin{array}{c}\text { Sprouting frequency } \\
(\%)\end{array}$ \\
\hline 1 & Fragile beads & 25 & Fragile beads \\
2 & Fragile beads & 50 & $26.44 \pm 1.73^{\mathrm{c}}$ \\
3 & $55.73 \pm 1.58^{\mathrm{a}}$ & 75 & $42.31 \pm 2.81^{\mathrm{b}}$ \\
4 & $44.11 \pm 1.82^{\mathrm{b}}$ & 100 & $62.79 \pm 1.87^{\mathrm{a}}$ \\
\hline CD & 5.92 & $\mathrm{CD}$ & 2.53 \\
\hline
\end{tabular}
Each mean is calculated from three replicates and represented as Mean \pm SE. Different letters in 630 the columns depicts the significant differences from each other (Duncan's multiple range tests, $P$ $631<0.05)$. Critical Difference (CD) at 5.0 percent level. 
643 Table 2 Response of storage temperature and duration of encapsulated seeds and its sprouting 644 potential after sub-culture on MS medium enriched $5.0 \mathrm{mg} / 1$ 6-Benzylaminopurine (BAP).

\begin{tabular}{cccc}
\hline $\begin{array}{c}\text { Storage temperature } \\
\left({ }^{\mathbf{o}} \mathbf{C}\right)\end{array}$ & $\begin{array}{c}\text { Storage span } \\
\text { duration } \\
(\text { Days })\end{array}$ & $\begin{array}{c}\text { Sprouting potential } \\
(\%)\end{array}$ & $\begin{array}{c}\text { Number of sprouted } \\
\text { shoots/ capsule }\end{array}$ \\
\hline 4 & 30 & $80.24 \pm 1.01^{\mathrm{a}}$ & $6.07 \pm 0.19^{\mathrm{a}}$ \\
& 60 & $68.03 \pm 1.51^{\mathrm{b}}$ & $4.43 \pm 0.40^{\mathrm{bc}}$ \\
& 90 & $42.89 \pm 6.04^{\mathrm{cd}}$ & $2.68 \pm 0.09^{\mathrm{d}}$ \\
& 180 & 0.0 & 0.0 \\
& 30 & $68.81 \pm 2.59^{\mathrm{b}}$ & $5.47 \pm 0.35^{\mathrm{ab}}$ \\
& 60 & $47.69 \pm 1.38^{\mathrm{c}}$ & $3.13 \pm 0.38^{\mathrm{cd}}$ \\
& 90 & $33.53 \pm 7.15^{\mathrm{d}}$ & $1.80 \pm 0.25^{\mathrm{d}}$ \\
& 180 & 0.0 & 0.0 \\
\hline $\mathrm{CD}$ & 6.10 & 0.86 \\
\hline
\end{tabular}

645 Each mean is calculated from three replicates and represented as Mean \pm SE. Different letters in 646 the columns depicts the significant differences from each other (Duncan's multiple range tests, $P$ $647<0.05)$. Critical Difference $(C D)$ at 5.0 percent level.

648

649

650 
Table 3 Response of the node explant maintained under slow growth conditions.

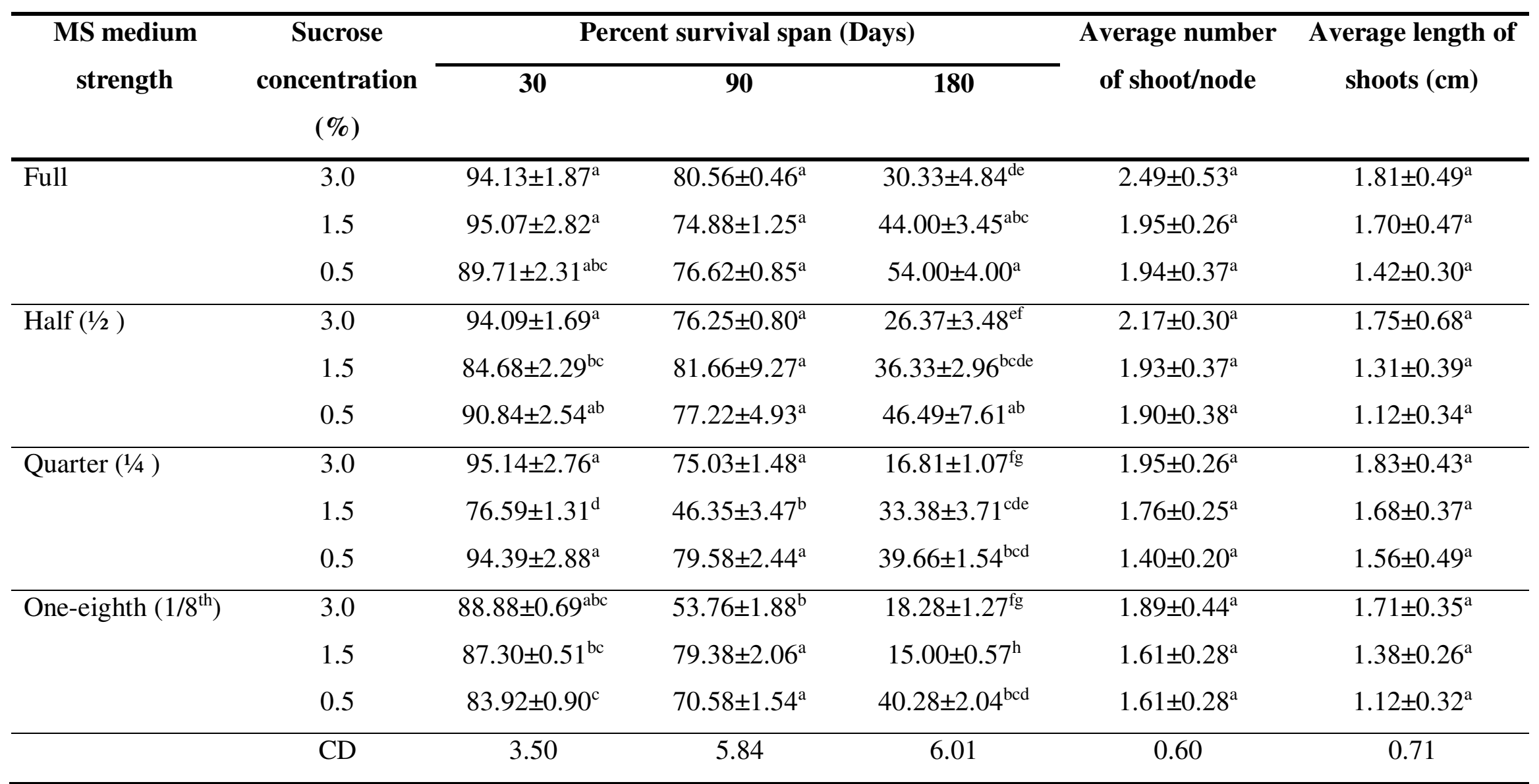

Mean value is calculated from three replicates and represented as Mean \pm SE. Different letters in the columns depicts the significant differences from each-other. (Duncan's multiple range test, $P<0.05$ ). Critical Difference (CD) at 5.0 percent level. 
654 Table 4 Response of node explant stored for different time span on one-eighth $\left(1 / 8^{\text {th }}\right)$ MS 655 medium containing 0.5 percent sucrose with different concentrations of abscisic acid (ABA).

\begin{tabular}{|c|c|c|c|c|c|}
\hline \multirow{2}{*}{$\begin{array}{l}\text { Abscisic acid } \\
\text { (ABA) } \\
\text { concentration } \\
\text { mg/l }\end{array}$} & \multicolumn{3}{|c|}{ Percent survival span (Days) } & \multirow{2}{*}{$\begin{array}{c}\text { Average } \\
\text { number of } \\
\text { shoots }\end{array}$} & \multirow{2}{*}{$\begin{array}{c}\text { Average } \\
\text { length of } \\
\text { shoots }(\mathrm{cm})\end{array}$} \\
\hline & 30 & 90 & 180 & & \\
\hline 0.0 & $76.00 \pm 2.84^{\mathrm{b}}$ & $50.22 \pm 1.76^{\mathrm{a}}$ & 0.0 & $2.30 \pm 0.46^{\mathrm{a}}$ & $1.30 \pm 0.08^{\mathrm{a}}$ \\
\hline 0.5 & $84.66 \pm 2.35^{\mathrm{a}}$ & $55.00 \pm 2.88^{\mathrm{a}}$ & $40.36 \pm 1.01^{\mathrm{a}}$ & $1.32 \pm 0.11^{\mathrm{b}}$ & $0.50 \pm 0.14^{b}$ \\
\hline 1.0 & $74.33 \pm 2.35^{\mathrm{b}}$ & $35.00 \pm 1.60^{\mathrm{b}}$ & $28.70 \pm 1.75^{\mathrm{b}}$ & $1.46 \pm 0.08^{\mathrm{b}}$ & $0.50 \pm 0.08^{b}$ \\
\hline 2.0 & $53.96 \pm 1.88^{c}$ & $34.16 \pm 2.20^{b}$ & $26.88 \pm 1.68^{b}$ & $1.91 \pm 0.16^{\mathrm{a}}$ & $0.57 \pm 0.12^{b}$ \\
\hline $\mathrm{CD}$ & 4.39 & 4.58 & 2.15 & 0.25 & 0.23 \\
\hline
\end{tabular}

Mean value is calculated from three replicates. Different letters in the columns depicts the 657 significant differences from each other (Duncan's multiple range tests, $P<0.05$ ). Critical 658 Difference (CD) at 5.0 percent level.

659 Table 5 Rooting of green, actively growing microshoots cultured on half (1/2) strength MS 660 medium supplemented with different concentrations of Indole-3-acetic acid (IAA).

\begin{tabular}{c|c|c|c}
\hline $\begin{array}{c}\text { Concentration of IAA } \\
(\mathbf{m g} / \mathbf{l})\end{array}$ & \multicolumn{3}{|c}{ Response } \\
\cline { 3 - 5 } & Rooting frequency (\%) & $\begin{array}{c}\text { Mean number of } \\
\text { roots/shoot }\end{array}$ & $\begin{array}{c}\text { Average length of roots } \\
(\mathbf{c m})\end{array}$ \\
\hline 0.0 & 0.0 & 0.0 & 0.0 \\
1.0 & $31.66 \pm 4.40^{\mathrm{b}}$ & $1.74 \pm 0.29^{\mathrm{c}}$ & $2.13 \pm 0.07^{\mathrm{a}}$ \\
2.0 & $43.22 \pm 2.43^{\mathrm{a}}$ & $1.82 \pm 0.09^{\mathrm{c}}$ & $1.87 \pm 0.19^{\mathrm{ab}}$ \\
4.0 & $54.00 \pm 3.05^{\mathrm{a}}$ & $3.25 \pm 0.14^{\mathrm{b}}$ & $1.11 \pm 0.05^{\mathrm{c}}$ \\
6.0 & $45.00 \pm 2.88^{\mathrm{a}}$ & $4.66 \pm 0.56^{\mathrm{a}}$ & $1.29 \pm 0.27^{\mathrm{bc}}$ \\
8.0 & Callus & Callus & Callus \\
\hline CD & 6.17 & 0.62 & 0.33 \\
\hline
\end{tabular}

Mean value is calculated from three replicates and represented as Mean \pm SE. Different letters in 662 the columns depicts the significant differences from each other (Duncan's multiple range test, $P$ $663<0.05)$.Critical Difference $(\mathrm{CD})$ at 5.0 percent level. 
664 Table 6 Details of SCoT primer, sequence of primer, annealing temperature $\left({ }^{\circ} \mathrm{C}\right)$, number of scorable 665 and total amplified bands for true-to-type clonal fidelity analysis.

\begin{tabular}{|c|c|c|c|c|c|}
\hline S No. & $\begin{array}{l}\text { SCoT } \\
\text { Primer }\end{array}$ & Sequence (5'-3') & $\operatorname{Tm}\left({ }^{\circ} \mathbf{C}\right)$ & $\begin{array}{c}\text { Amplified } \\
\text { number of } \\
\text { scorable } \\
\text { bands/primer }\end{array}$ & Total bands \\
\hline 1 & SCoT 5 & CAACAATGGCTACCACGA & 54 & 6 & 36 \\
\hline 2 & SCoT 6 & CAACAATGGCTACCACGC & 56 & 8 & 46 \\
\hline 3 & SCoT 8 & CAACAATGGCTACCACGT & 54 & 2 & 12 \\
\hline 4 & SCoT 9 & CAACAATGGCTACCAGCA & 54 & 6 & 36 \\
\hline 5 & SCoT 10 & CAACAATGGCTACCAGCC & 56 & 6 & 34 \\
\hline 6 & SCoT 11 & AAGCAATGGCTACCACCA & 50 & 4 & 20 \\
\hline 7 & SCoT 24 & CACCATGGCTACCACCAT & 56 & 5 & 28 \\
\hline 8 & SCoT 25 & ACCATGGCTACCACCGGG & 61 & 6 & 34 \\
\hline 9 & SCoT 26 & ACCATGGCTACCACCGTC & 58 & 8 & 44 \\
\hline 10 & SCoT 27 & ACCATGGCTACCACCGTG & 58 & 5 & 30 \\
\hline 11 & SCoT 28 & CCATGGCTACCACCGCCA & 61 & 8 & 46 \\
\hline 12 & SCoT 29 & CCATGGCTACCACCGGCC & 63 & 5 & 30 \\
\hline 13 & SCoT 30 & CCATGGCTACCACCGGCG & 63 & 4 & 22 \\
\hline 14 & SCoT 31 & CCATGGCTACCACCGCCT & 61 & 5 & 26 \\
\hline \multicolumn{4}{|l|}{ Total } & 78 & 444 \\
\hline
\end{tabular}



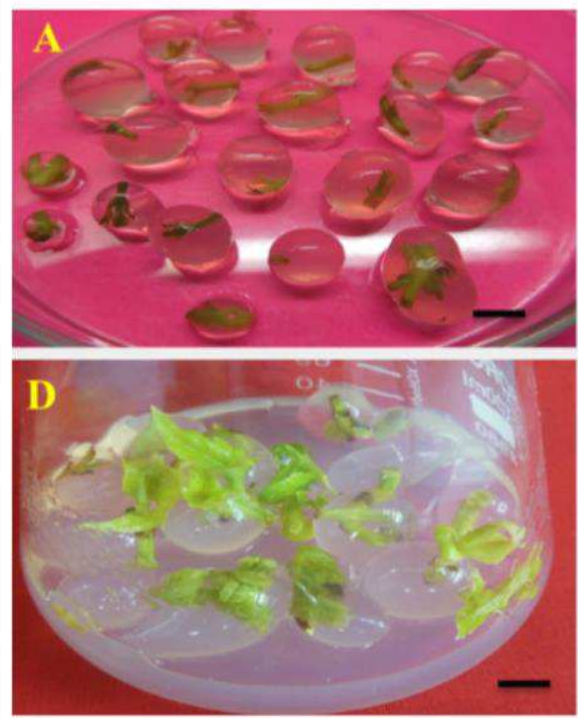
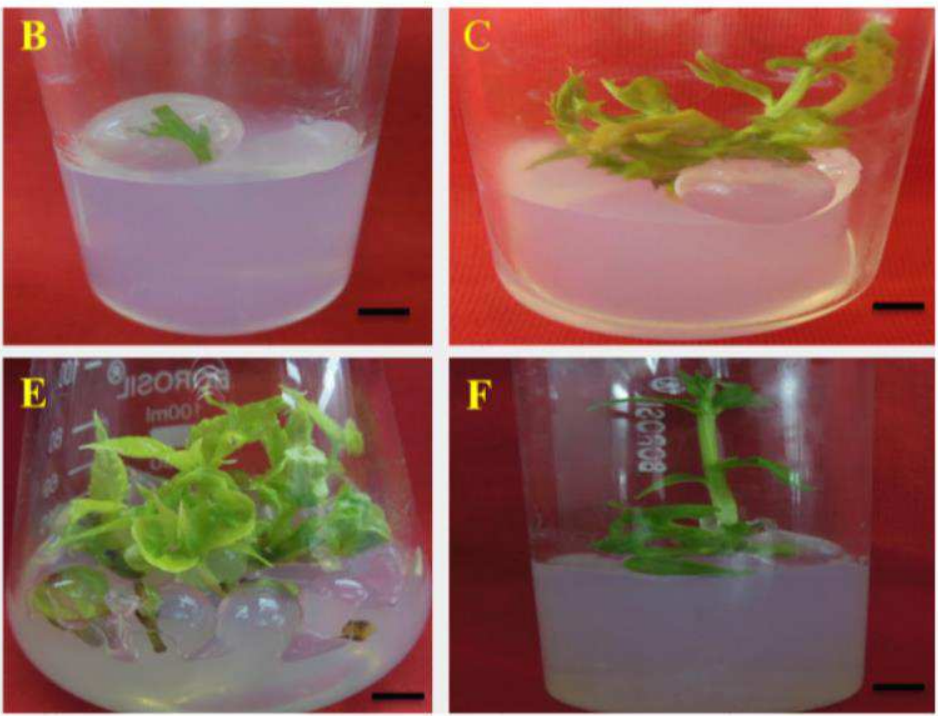

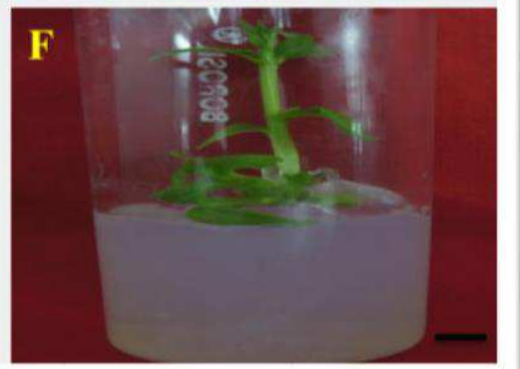

671

672 Fig.1 Encapsulated seeds of $N$. arbor-tristis L. and its sprouting potential (A) Encapsulated seeds

673 (B) Encapsulated seeds cultured on sprouting medium (C) Sprouted shoots from encapsulated 674 seeds, (D-E) Sprouting in stored encapsulated seeds, (F) Elongation of shoots.

675

676

677

678

679

680

681

682

683

684

685

686

687

688

689

690 
(A)

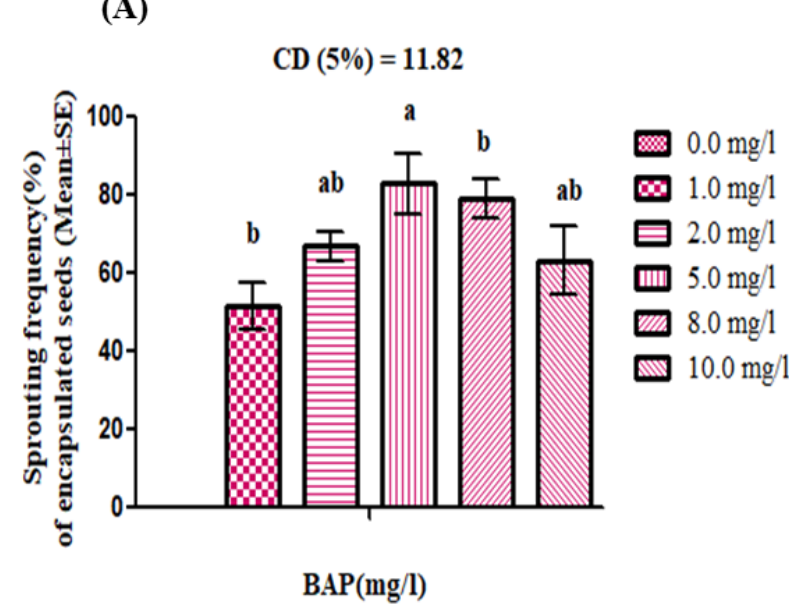

(B)

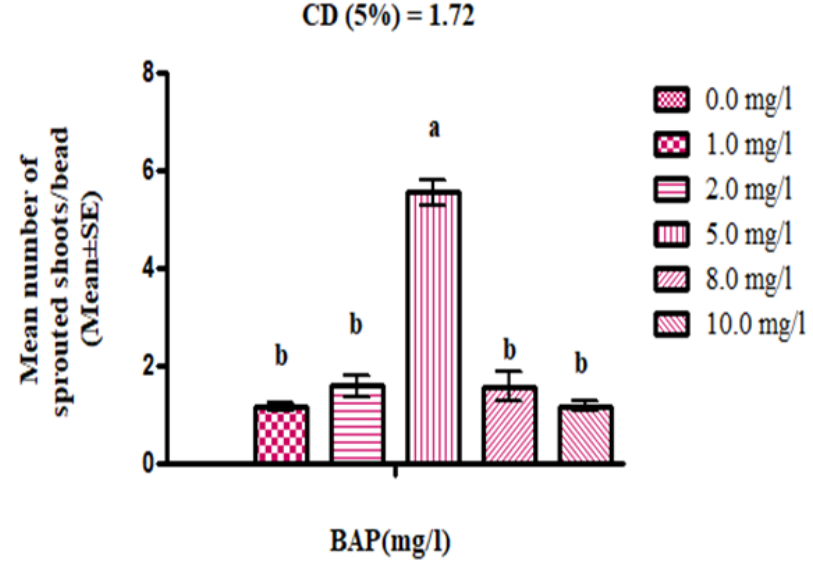

693

694

695

696

697 698

699

700

701

702

703

704

.

03

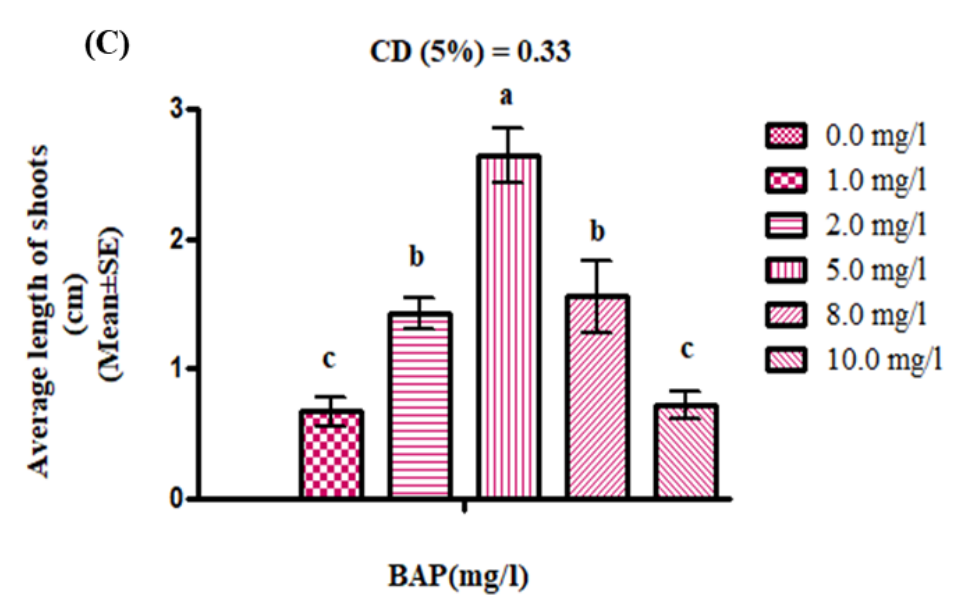

Fig.2 Picture in vertical bar showed the sprouting response of encapsulated seeds cultured on MS medium enriched with 6-Benzylaminopurine (BAP). Each mean is calculated from three replicates. Different letters above the bar indicate the significant differences from each other (Duncan's multiple range tests, $P<0.05$ ).Critical Difference $(\mathrm{CD})$ at 5 percent level

. 

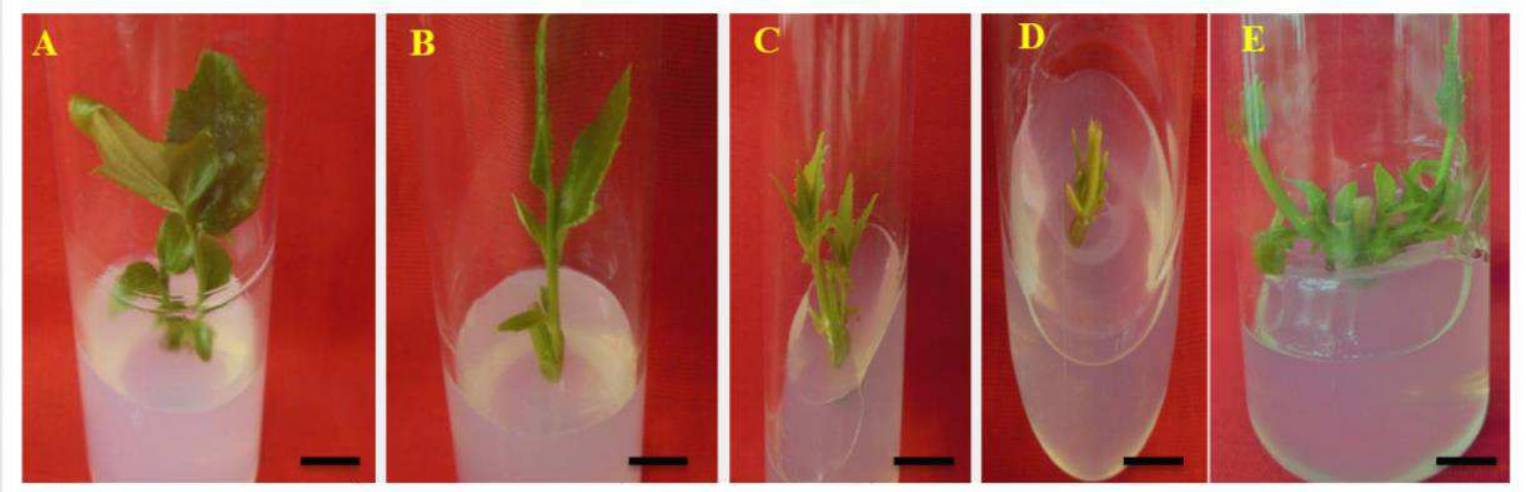

Fig. 3 Photographs showed the conservation of $N$. arbor-tristis L. under slow growth condition (A) Node explant maintained on full strength MS+0.5 percent sucrose medium, (B) Explant maintain on half $(1 / 2)$ strength $\mathrm{MS}+0.5$ percent sucrose (C)

(C) Explant maintain on quarter $(1 / 4)$ 
(A)

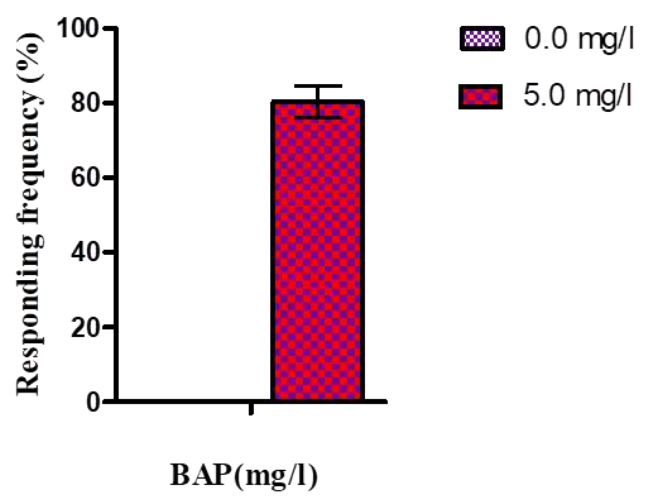

(C)

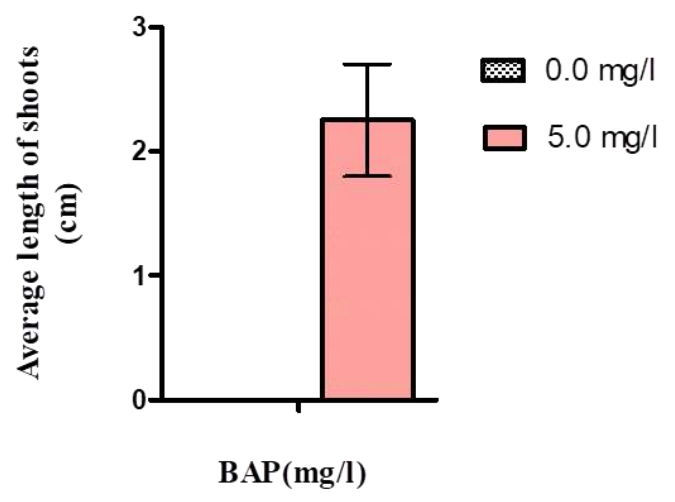

(B)

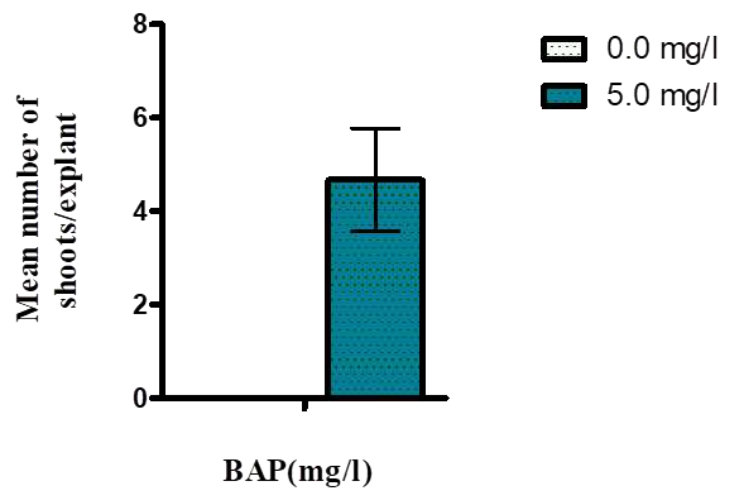

732 Fig. 4 Vertical bar picture showed mean morphogenic recovery potential from stored nod explant 733 on 6-Benzylaminopurine (BAP) enriched MS medium. (A) Responding frequency, (B) Average 734 mean number of shoots/ explant, (C) Average length of shoots (cm). 


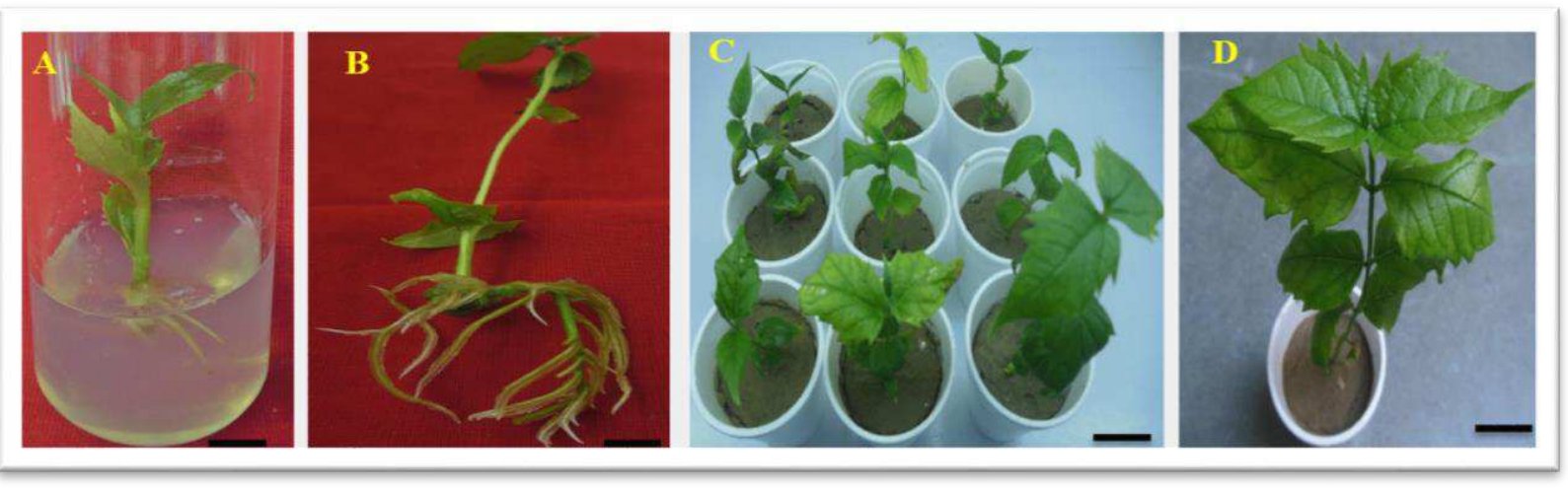

745

746

747

748

749

750

751

752

753

754

755

756

757

758

759

760

761

762

763

764

765

766

767

768

9

Fig.5 (A) Picture of in- vitro rooting of green actively growing shoot on half (1/2) strength MS medium enriched with $4 \mathrm{mg} / \mathrm{l}$ Indole-3-acetic acid (IAA), (B) Rooted plant, (C) Hardened plants, (D) Hardened healthy plant ready to transfer in to field. Bar $5.0 \mathrm{~mm}$.

0

1

52

3




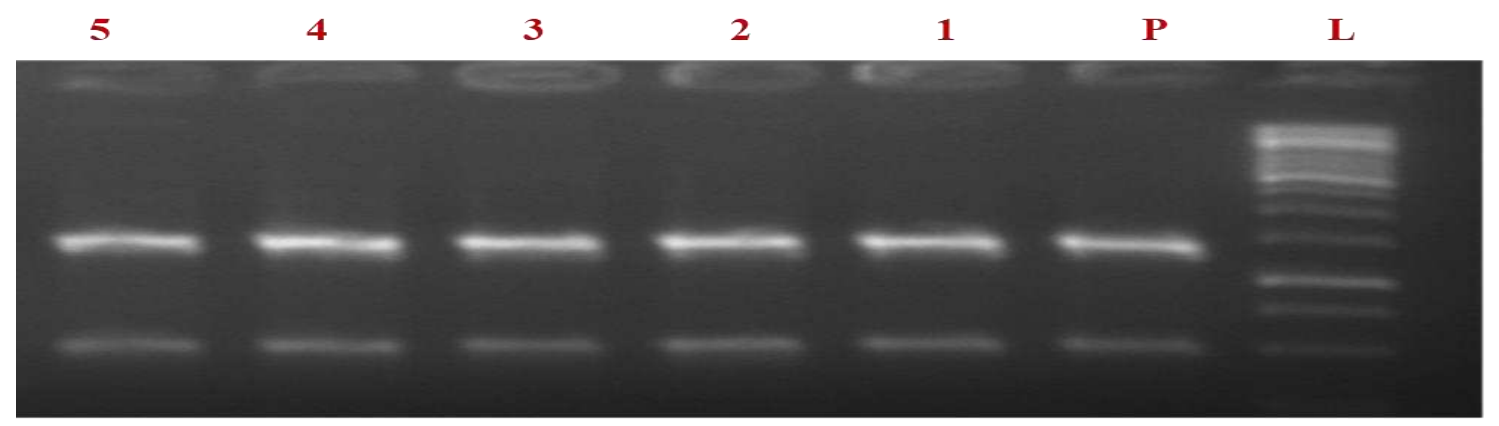

500

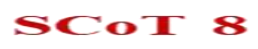

$\begin{array}{llllllll}5 & 4 & 3 & 2 & 1 & \text { P }\end{array}$

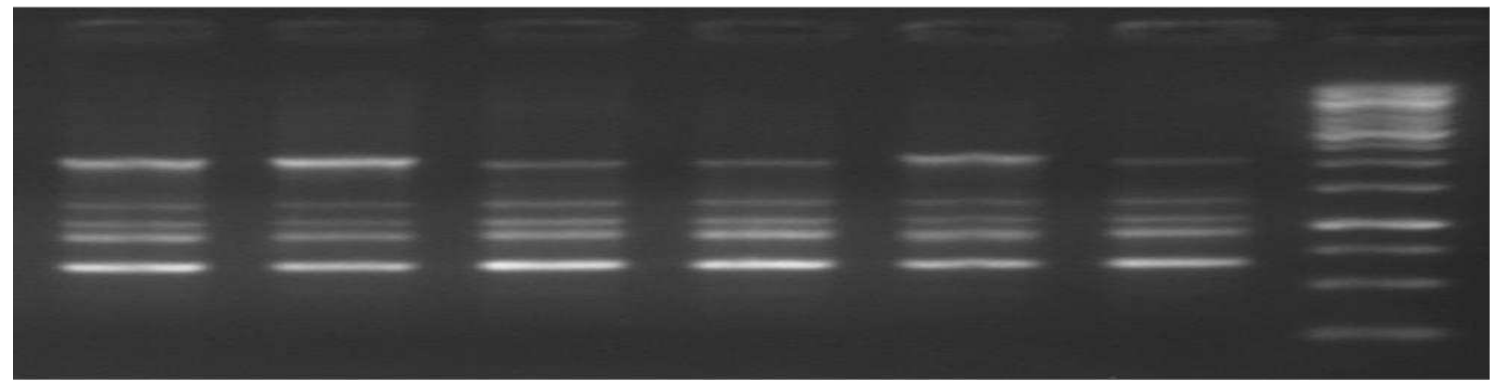

772 Fig.6 Gel picture depicts SCoT amplification banding pattern. In photograph, an alphabetical 773 letter $(\mathrm{L})$ represents $1 \mathrm{~Kb}$ ladder, letter $(\mathrm{P})$ denotes the source parent mother plant of $N$. arbor774 tristis L., and numeric number 1 to 5 denotes bands of tissue culture recovered acclimatized 775 hardened plants 


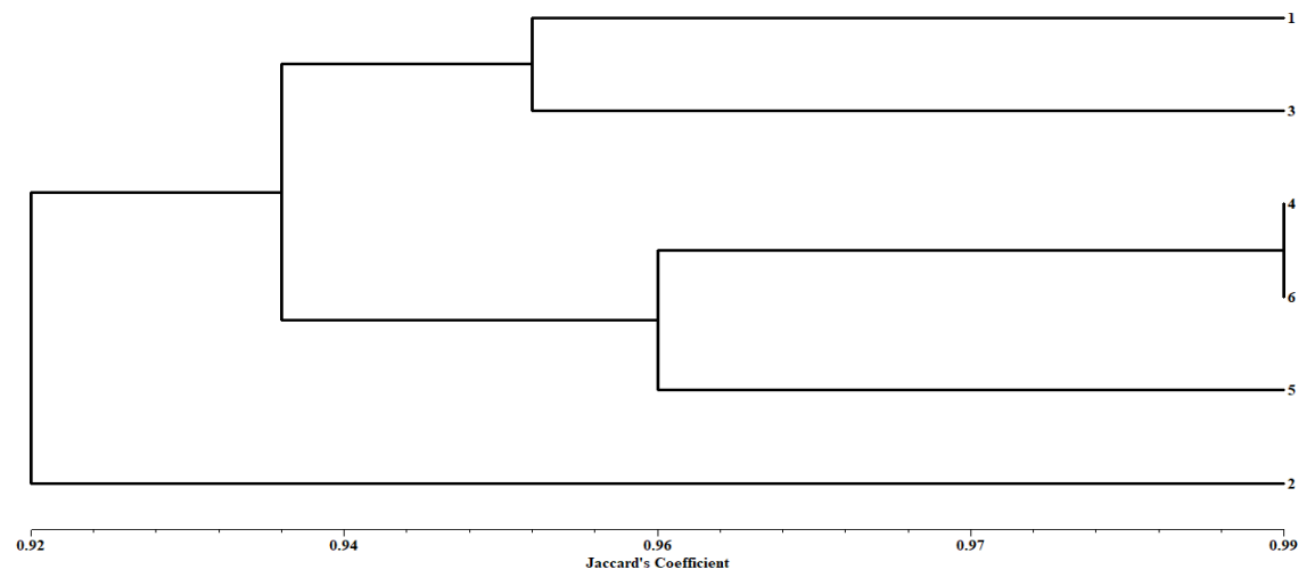

787 Fig. 7 Picture of maximum likelihood tree based on Jaccard's average similarity coefficient 788 originated through UPGMA matrix of tissue culture recovered acclimatized plants of $N$. arbor789 tristis L.

790 